\title{
Effects of baicalin on inflammatory reaction, oxidative stress and PKDI and NF-kB protein expressions in rats with severe acute pancreatitis ${ }^{1}$
}

Yunzhong Qian', Yi Chen", Linyang Wang", Jinfa Tou"

'UG, Department of General Surgery, The Children's Hospital, School of Medicine, Zhejiang University, Hangzhou, China. Design of the study, critical revision, final approved.

"MS, Department of General Surgery, The Children's Hospital, School of Medicine, Zhejiang University, Hangzhou, China. Design of the study, acquisition of data, statistical analysis, critical revision, final approved.

\section{Abstract}

Purpose: To investigate the effects of baicalin on inflammatory reaction, oxidative stress and protein kinase D1 (PKD1) and nuclear factor-kappa B (NF-KB) protein expressions in severe acute pancreatitis (SAP) rats.

Methods: Sixty rats were divided into sham operation, model, and low-, medium- and highdose baicalin group. SAP model was established in later 4 groups. The later 3 groups were injected with $0.1,0.2$ and $0.4 \mathrm{ml} / 100 \mathrm{~g} 5 \%$ baicalin injection, respectively. At $12 \mathrm{~h}$, the serum SAP related indexes and inflammatory factors, peripheral blood $\mathrm{CD}_{3}$ and $\gamma \delta T$ cell percentages, wet/dry ratio and pancreas ascites volume, oxidative stress indexes and PKD1 and NF-KB protein expressions in pancreatic tissue were determined.

Results: Compared with model group, in high-dose baicalin group the wet/dry ratio and ascites volume, serum amylase level, phospholipase $A_{2}$ activity, TNF- $\alpha$, IL-1 and IL- 6 levels, and pancreatic malondialdehyde level and PKD1 and NF-KB protein expression were significantly decreased $(P<0.05)$, and peripheral blood CD3 and $\gamma \delta T$ cell percentages and pancreatic superoxide dismutase and glutathione peroxidase levels were significantly increased $(P<$ 0.05).

Conclusion: Baicalin can resist the inflammatory reaction and oxidative stress, and downregulate protein kinase D1 and nuclear factor-kappa B protein expressions, thus exerting the protective effects on severe acute pancreatitis in rats.

Key words: Pancreatitis. Oxidative Stress. Protein Kinases. NF-kappa B. Rats. 


\section{Introduction}

Acute pancreatitis is an inflammatory disease of pancreatitis characterized by pancreatic edema, hemorrhagic necrosis and inflammatory cell infiltration. It is usually accompanied by systemic inflammatory response syndrome and multiple organ failure ${ }^{1}$. Severe acute pancreatitis (SAP) is a special type of acute pancreatitis, which has dangerous condition, serious complications and high mortality ${ }^{2}$. The treatment of SAP is always a difficult problem in the medical field, of which the main reason is that the pathogenesis of SAP is not clear enough, and there is no effective standard for treatment ${ }^{3}$. Radix Scutellariae is one of the commonly used Chinese medicinal herbs in Asia region, and has a long history of clinical application. Baicalin belongs to flavonoids. It is the main component extracted from the Radix Scutellariae ${ }^{4}$. It is found that baicalin has the functions ofscavenging avariety of free radicals, antioxidation and anti-inflammation ${ }^{5,6}$. In addition, baicalin has protective effect on immune $^{7}$, cardiovascular ${ }^{8}$, digestive ${ }^{9}$ and nervous system ${ }^{10}$. This study investigated the effects of baicalin on inflammatory reaction, oxidative stress and protein kinase D1 and nuclear factor-kappa B protein expressions in rats with SAP. The objective was to provide a theoretical basis for the development of baicalin related medicines for treatment of SAP.

\section{Methods}

This study was carried out in strict accordance with the recommendations in the Guide for the Care and Use of Laboratory Animals of the National Institutes of Health. The animal use protocol has been reviewed and approved by the Institutional Animal Care and Use Committee of Zhejiang University.

\section{Animal grouping and treatment}

Sixty SD rats $(240 \pm 30$ g; Zhejiang Experimental Animal Center, Hangzhou, China) were randomly divided into sham operation group, model group, and low-, middle- and high-dose baicalin group, 12 rats in each group. In the sham operation group, the abdomen was cut open, with mildly rubbing the pancreas and turning over the intestinal canal for $5 \mathrm{~min}$, followed by abdominal closure. In other 4 groups, the SAP model was established. After abdominal incision, $5 \%$ sodium taurocholate (Sigma-Aldrich Corp., MO, USA) was injected retrogradely into bile duct, with dose of 0.1 $\mathrm{ml} / 100 \mathrm{~g}$ body weight, followed by abdominal closure. In low-, middle- and high-dose baicalin groups, after $5 \mathrm{~min}$ from SAP modeling, 5\% baicalin injection (Shaanxi Saide Science and Technology Development Co., Ltd., Xi'an, China) was injected through the tail vein (2 $\mathrm{ml} / \mathrm{h}$ ), with dose of $0.1,0.2$ and $0.4 \mathrm{ml} / 100 \mathrm{~g}$, respectively. The sham operation and model groups were injected with equal amount of physiological saline.

\section{Determination of SAP related indexes and inflammatory factors}

At the $12 \mathrm{~h}$ after surgery, $10 \mathrm{ml}$ of abdominal artery blood was taken from the rats. The serum amylase level and phospholipase $A_{2}$ $\left(\mathrm{PLA}_{2}\right)$ activity were determined using automatic blood biochemistry analyzer. The serum tumor necrosis factor- $\alpha$ (TNF- $\alpha$ ), interleukin-1 (IL-1) and interleukin-6 (IL-6) levels were detected by enzyme linked immunosorbent assay. The procedures were in accordance to the instructions of kits (Sigma-Aldrich Corp., MO, USA).

Determination of peripheral blood $\mathrm{CD}_{3}$ and $\mathrm{\gamma} \delta \mathrm{T}$ cell percentages

Two milliliter of whole blood was added 
to the anticoagulant tube containing $30 \mu \mathrm{L}$ $10 \%$ EDTA and $30 \mu \mathrm{L}$ aprotinin (Sigma-Aldrich Corp., MO, USA). Four dedicated test tubes were taken, and $100 \mu \mathrm{L}$ of anticoagulant whole blood was added to each tube. Then, $30 \mu \mathrm{L}$ of $\mathrm{CD}_{3}$-FITC antibody and $\gamma \delta T$ TE antibody and the same-type control antibodies (Fuzhou Maixin Biotechnology Development Co., Ltd., Fuzhou, China) were added to 4 tubes, respectively, followed by fully mixing and standing avoiding light for $20 \mathrm{~min}$ at room temperature. Each tube was added with $2 \mathrm{ml}$ of red cell lysate (Fuzhou Maixin Biotechnology Development Co., Ltd., Fuzhou, China), followed by gently mixing standing avoiding light for $5 \mathrm{~min}$. After the liquid in the tube was transparent, the mixture was centrifuged at $1500 \mathrm{r} / \mathrm{min}$ for $5 \mathrm{~min}$. The supernatant was discarded. The precipitate was washed with $2 \mathrm{ml}$ of PBS (Sigma-Aldrich Corp., MO, USA) for 2 times, and then was suspended with $0.5 \mathrm{ml}$ of PBS. The $\mathrm{CD}_{3}$ and $\gamma \delta \mathrm{T}$ cell percentages were detected by FACSCantoTM II flow cytometry (Becton, Dickinson and Company, NJ, USA).

\section{Determination of wet/dry ratio and ascites volume of pancreas}

The rats were executed. The pancreatic tail tissue was taken and the wet weight was measured with electronic balance. Then, the pancreatic tail tissue was dried in $80^{\circ} \mathrm{C}$ baking oven for $24 \mathrm{~h}$, followed by measurement of dry weight. The wet/dry ratio of pancreas was calculated.

Determination of superoxide dismutase, glutathione peroxidase and malondialdehyde levels in pancreatic tissue

Pancreatic tissue was homogenized using $4^{\circ} \mathrm{C}$ physiological saline. After centrifuging at $2000 \mathrm{r} / \mathrm{min}$ and $4^{\circ} \mathrm{C}$ for $15 \mathrm{~min}$, the supernatant was obtained for further use. The superoxide dismutase (SOD) level was detected by xanthine oxidase method ${ }^{11}$. The glutathione peroxidase (GSH-Px) level was measured by reduced glutathione depletion method ${ }^{12}$. The content of malondialdehyde (MDA) was analyzed by thiobarbituric acid colorimetric assay $^{13}$. The reagents were provided by SigmaAldrich Corp. (MO, USA).

\section{Determination of protein kinase D1 and} nuclear factor-kappa $B$ protein expressions in pancreatic tissue

Expressions of protein kinase D1 (PKD1) and nuclear factor-kappa B (NF-kB) protein in pancreatic tissue were determined using western blot assay. The pancreatic tissue was homogenized. The protein was extracted using RIPA lysis buffer (Sigma-Aldrich Corp., MO, USA). The protein concentration was determined by Coomassie brilliant blue method. $60 \mu \mathrm{g}$ protein was used for the SDSPAGE (Sigma-Aldrich Corp., MO, USA), then the protein was transferred to the PVDF membrane (Sigma-Aldrich Corp., MO, USA). After blocking using I\% BSA (Sigma-Aldrich Corp., MO, USA), the PVDF membranes were incubated with primary antibody overnight at $4^{\circ} \mathrm{C}$, followed by washing with PBS. The horseradish peroxidase-labeled second antibody was added, followed by incubation at $37^{\circ} \mathrm{C}$ for $1 \mathrm{~h}$. Visualization was accomplished by the enhanced chemiluminescence. The intensity of bands was calculated using IPP6.0 imaging analysis software (Media Cybernetics Inc., MA, USA). The primary and secondary antibodies were provided by Shanghai Sangon Biological Engineering Technology And Service Co., Ltd. (Shanghai, China). $\beta$-actin (Sigma-Aldrich Corp., MO, USA) was used as the internal reference.

\section{Statistical analysis}

All statistical analysis was carried out using SPSS 19.0 software (SPSS Inc., Chicago, IL, USA). The data were presented as mean \pm SD. 
The difference between two groups was analyzed using one-way ANOVA with LSD post hoc test. $\mathrm{P}<0.05$ was considered as statistically significant.

\section{- Results}

Effect of baicalin on mortality of SAP rats

In sham operation, middle- and highdose baicalin groups, no rat died within $12 \mathrm{~h}$ after surgery. In model and low-dose baicalin groups, there were 2 and 1 mortalities of rats, respectively.
Effect of baicalin on wet/dry ratio and ascites volume of pancreas in SAP rats

Compared with sham operation group, the wet/dry ratio of pancreas in rats in model group was significantly increased $(P<0.05)$. Compared with model group, the wet/dry ratio in middle- and high-dose baicalin groups was significantly decreased, respectively $(P<0.05)$. Compared with sham operation group, the ascites volume of pancreas in model group was significantly increased $(P<0.05)$. Compared with model group, the ascites volume in highdose baicalin group was significantly decreased, respectively $(\mathrm{P}<0.05)$ (Table 1$)$.

Table 1 - Effect of baicalin on wet/dry ratio and ascites volume of pancreas in rats.

\begin{tabular}{lll}
\hline Group & Wet/dry ratio & Ascites volume (ml) \\
\hline Sham operation & $3.21 \pm 0.65$ & $0.63 \pm 0.11$ \\
Model & $8.45 \pm 1.12^{\mathrm{a}}$ & $11.23 \pm 2.51^{\mathrm{a}}$ \\
Low-dose baicalin & $7.21 \pm 0.66^{\mathrm{a}}$ & $10.37 \pm 1.94^{\mathrm{a}}$ \\
Middle-dose baicalin & $6.38 \pm 0.72^{\mathrm{ab}}$ & $9.16 \pm 1.82^{\mathrm{a}}$ \\
High-dose baicalin & $5.52 \pm 0.57^{\mathrm{ab}}$ & $6.29 \pm 1.19^{\mathrm{abc}}$ \\
\hline
\end{tabular}

${ }^{a} \mathrm{P}<0.05$ compared with sham operation group; ${ }^{b} \mathrm{P}<0.05$ compared with model group; ${ }^{\mathrm{c}}<0.05$ compared with low-dose baicalin group. SAP, severe acute pancreatitis.

Effect of baicalin on serum amylase level and $P L A_{2}$ activity in SAP rats

Table 2 showed that, compared with sham operation group, the serum amylase level and PLA ${ }_{2}$ activity in rats in model group were significantly increased, respectively $(\mathrm{P}<$ 0.05). Compared with model group, the serum amylase level and PLA ${ }_{2}$ activity in middle- and high-dose baicalin groups were significantly decreased, respectively $(P<0.05)$.

Table 2 - Effect of baicalin on serum amylase level and PLA ${ }_{2}$ activity in rats.

\begin{tabular}{lll}
\hline Group & Amylase (U/L) & PLA 2 activity (nmol/min·ml) \\
\hline Sham operation & $456.45 \pm 67.18$ & $14.56 \pm 3.02$ \\
Model & $1131.17 \pm 112.43^{\mathrm{a}}$ & $72.28 \pm 14.23^{\mathrm{a}}$ \\
Low-dose baicalin & $1067.36 \pm 115.18^{\mathrm{a}}$ & $65.38 \pm 10.5^{\mathrm{a}}$ \\
Middle-dose baicalin & $834.18 \pm 93.83^{\mathrm{ab}}$ & $34.78 \pm 6.38^{\mathrm{ab}}$ \\
High-dose baicalin & $573.59 \pm 101.08^{\mathrm{bc}}$ & $19.31 \pm 4.61^{\mathrm{bc}}$ \\
\hline
\end{tabular}

${ }^{\mathrm{a}} \mathrm{P}<0.05$ compared with sham operation group; ${ }^{\mathrm{b}} \mathrm{P}<0.05$ compared with model group; $\mathrm{C}<0.05$ compared with low-dose baicalin group. SAP, severe acute pancreatitis; $\mathrm{PLA}_{2}$, phospholipase $\mathrm{A}_{2}$. 
Effect of baicalin on serum TNF- $\alpha, I L-1$ and IL-6 levels in SAP rats

As shown in Table 3, compared with sham operation group, the serum TNF- $\alpha, \mathrm{IL}-1$ and IL-6 levels in rats in model group were significantly increased, respectively $(P<0.05)$.
Compared with model group, the serum TNF- $\alpha$ level in high-dose baicalin group, IL-1 level in middle- and high-dose baicalin groups, and IL-6 level in low-, middle- and high-dose baicalin groups were significantly decreased, respectively $(P<0.05)$.

Table 3 - Effect of baicalin on serum TNF- $\alpha$, IL-1 and IL-6 levels in rats.

\begin{tabular}{llll}
\hline Group & TNF- $\alpha(\mathrm{pg} / \mathrm{ml})$ & IL-1 $(\mathrm{pg} / \mathrm{ml})$ & IL-6 (pg/ml) \\
\hline Sham operation & $16.36 \pm 2.28$ & $53.11 \pm 11.01$ & $40.42 \pm 8.31$ \\
Model & $128.16 \pm 23.03^{\mathrm{a}}$ & $166.83 \pm 29.16^{\mathrm{a}}$ & $298.94 \pm 45.27^{\mathrm{a}}$ \\
Low-dose baicalin & $112.48 \pm 20.21^{\mathrm{a}}$ & $135.47 \pm 24.27^{\mathrm{a}}$ & $202.32 \pm 31.83^{\mathrm{ab}}$ \\
Middle-dose baicalin & $92.71 \pm 13.58^{\mathrm{a}}$ & $103.62 \pm 18.61^{\mathrm{ab}}$ & $196.17 \pm 29.72^{\mathrm{ab}}$ \\
High-dose baicalin & $68.94 \pm 9.17^{\mathrm{ab}}$ & $92.38 \pm 15.32^{\mathrm{ab}}$ & $173.05 \pm 26.62^{\mathrm{ab}}$ \\
\hline
\end{tabular}

${ }^{a} \mathrm{P}<0.05$ compared with sham operation group; ${ }^{\mathrm{b}} \mathrm{P}<0.05$ compared with model group. SAP, severe acute pancreatitis. TNF- $\alpha$, tumor necrosis factor- $\alpha$; IL-1, interleukin-1; IL-6, interleukin-6.

Effect of baicalin on peripheral blood $C D_{3}$ and $\gamma \delta \mathrm{T}$ cell percentages in SAP rats

Table 4 showed that, compared with sham operation group, the peripheral blood $\mathrm{CD}_{3}$ and $\gamma \delta \mathrm{T}$ cell percentages in rats in model group were significantly decreased, respectively $(P<0.05)$. Compared with model group, the peripheral blood $\mathrm{CD}_{3}$ and $\gamma \delta \mathrm{T}$ cell percentages in high-dose baicalin group were significantly increased, respectively $(\mathrm{P}<$ 0.05).

Table 4 - Effect of baicalin on peripheral blood $\mathrm{CD}_{3}$ and $\gamma \delta \mathrm{T}$ cells in rats.

\begin{tabular}{lll}
\hline Group & $\mathrm{CD}_{3}(\%)$ & $\gamma \delta T(\%)$ \\
\hline Sham operation & $71.41 \pm 6.16$ & $6.33 \pm 1.02$ \\
Model & $57.62 \pm 5.25^{\mathrm{a}}$ & $3.04 \pm 0.63^{\mathrm{a}}$ \\
Low-dose baicalin & $58.37 \pm 6.73^{\mathrm{a}}$ & $3.35 \pm 0.72^{\mathrm{a}}$ \\
Middle-dose baicalin & $59.25 \pm 4.43^{\mathrm{a}}$ & $4.17 \pm 0.53^{\mathrm{a}}$ \\
High-dose baicalin & $63.52 \pm 6.26^{\mathrm{abc}}$ & $5.01 \pm 0.95^{\mathrm{abc}}$ \\
\hline
\end{tabular}

${ }^{a} \mathrm{P}<0.05$ compared with sham operation group; ${ }^{\mathrm{b}} \mathrm{P}<0.05$ compared with model group; ${ }^{\mathrm{c}} \mathrm{P}<0.05$ compared with low-dose baicalin group. SAP, severe acute pancreatitis.

Effect of baicalin on SOD, GSH-PX and MDA levels in pancreatic tissue of SAP rats

Compared with the sham operation group, the SOD and GSH-Px levels in pancreatic tissue in model group were significantly decreased, respectively $(P<0.05)$, and the MDA level was significantly increased $(P<$
0.05). Compared the model group, the SOD and GSH-Px levels in middle- and high-dose baicalin groups were significantly increased, respectively $(P<0.05)$, and the MDA levels in middle- and high-dose baicalin groups were significantly decreased, respectively $(P<0.05)$ (Table 5). 
Table 5 - Effects of baicalin on SOD, GSH-Px and MDA levels in pancreatic tissue of rats.

\begin{tabular}{llll}
\hline Group & SOD (U/mgprot) & GSH-Px (U/mgprot) & MDA (mmol/mgprot) \\
\hline Sham operation & $174.45 \pm 19.73$ & $131.12 \pm 14.56$ & $1.39 \pm 0.67$ \\
Model & $126.12 \pm 18.01^{\mathrm{a}}$ & $76.57 \pm 11.03^{\mathrm{a}}$ & $7.31 \pm 1.23^{\mathrm{a}}$ \\
Low-dose baicalin & $131.47 \pm 14.36^{\mathrm{a}}$ & $86.32 \pm 10.12^{\mathrm{a}}$ & $6.34 \pm 0.98^{\mathrm{a}}$ \\
Middle-dose baicalin & $147.73 \pm 15.12^{\mathrm{ab}}$ & $104.17 \pm 12.93^{\mathrm{abc}}$ & $4.56 \pm 0.72^{\mathrm{ab}}$ \\
High-dose baicalin & $162.19 \pm 17.02^{\mathrm{abc}}$ & $117.95 \pm 13.08^{\mathrm{bc}}$ & $3.35 \pm 0.39^{\mathrm{abc}}$ \\
\hline aP<0.05 compared with sham operation group; $\mathrm{b}<0.05$ compared with model group; $\mathrm{P}<0.05$ compared with low-dose baicalin group. \\
SAP, severe acute pancreatitis; SOD, superoxide dismutase; GSH-Px, glutathione peroxidase; MDA, malondialdehyde.
\end{tabular}

Effect of baicalin on PKD1 and NF-KB protein expressions in pancreatic tissue of SAP rats

Compared with sham operation group, the PKD1 and NF-KB protein expression levels in pancreatic tissue of rats in model group were significantly increased $(P<0.05)$. Compared with model group, the PKD1 and NF-KB protein expression levels in middle- and high-dose baicalin group were significantly decreased, respectively $(P<0.05)$ (Table 6 , Figure 1).

Table 6 - Effects of baicalin on PKD1 and NF-KB protein expression in pancreatic tissue of rats.

\begin{tabular}{lll}
\hline Group & PKD1/ $\beta$-actin & NF-KB/ $\beta$-actin \\
\hline Sham operation & $0.04 \pm 0.01$ & $0.25 \pm 0.04$ \\
Model & $0.56 \pm 0.07^{\mathrm{a}}$ & $0.93 \pm 0.08^{\mathrm{a}}$ \\
Low-dose baicalin & $0.48 \pm 0.06^{\mathrm{a}}$ & $0.87 \pm 0.09^{\mathrm{a}}$ \\
Middle-dose baicalin & $0.23 \pm 0.04^{\mathrm{abc}}$ & $0.57 \pm 0.07^{\mathrm{ab}}$ \\
High-dose baicalin & $0.12 \pm 0.02^{\mathrm{abc}}$ & $0.42 \pm 0.05^{\mathrm{bc}}$ \\
\hline
\end{tabular}

${ }^{a} \mathrm{P}<0.05$ compared with sham operation group; ${ }^{\mathrm{b}} \mathrm{P}<0.05$ compared with model group; ${ }^{\mathrm{c}}<<0.05$ compared with low-dose baicalin group. PKD1, protein kinase D1; NF-KB, nuclear factor-kappa B.

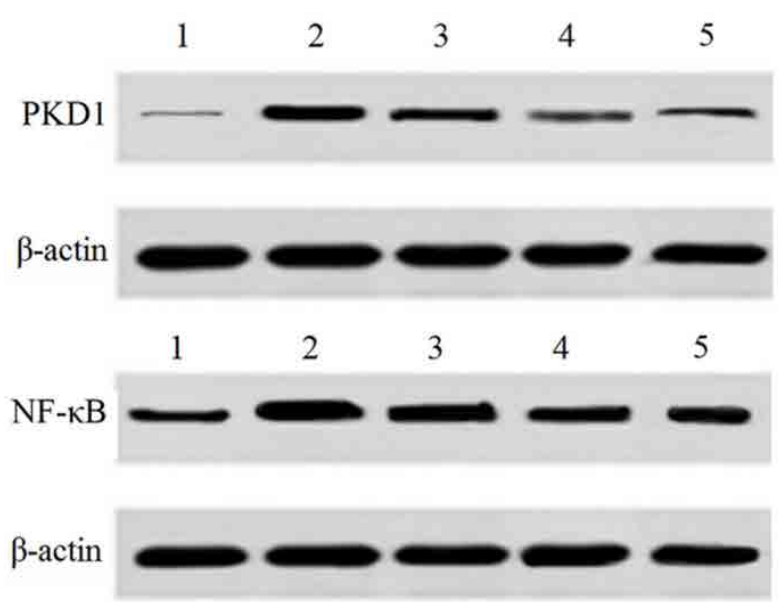

Figure 1 - Effects of baicalin on PKD1 and NF-KB protein expression in pancreatic tissue of rats. 1. Sham operation; 2. Model; 3. Low-dose baicalin; 4. Middle-dose baicalin; 5. High-dose baicalin. PKD1, protein kinase D1; NF-kB, nuclear factor-kappa B.

\section{Discussion}

In this study, the SAP model of rats was successfully established, and the effects of baicalin on SAP were investigated. Results showed that, baicalin could decrease the mortality, wet/dry ratio and ascites volume of pancreas of SAP rats. In addition, baicalin could decrease the serum amylase level and $\mathrm{PLA}_{2}$ activity in SAP rats. This indicates that, baicalin has obvious protective effects on SAP rats.

Excessive activation of inflammatory cytokines has a significant causal relationship with the development of systemic inflammatory response syndrome and multiple organ dysfunetion syndrome ${ }^{14}$. TNF- $\alpha$ is an important regulator of physiological and pathological 
changes in the body during infection ${ }^{15}$. It is mainly produced by mononuclear macrophage. It is found that, TNF- $\alpha$ is the first factor which level is firstly increased in SAP, and plays a key role in the pathogenesis of SAP. Excessive TNF- $\alpha$ can promote the production of other cytokines, leading to the linkage and amplification effects ${ }^{16}$. IL-1 and IL-6 are the main cytokines in acute phase response of SAP. It is reported that, IL-1 is the important factor for continuous pancreatic necrosis and aggravation of the systemic illness. IL- 6 in is not expressed in normal physiological. It is released by a variety of cells under condition of inflammatory stimuli. The level of IL- 6 is positively correlated with the SAP severity and incidence of related complications ${ }^{17}$. Therefore, the level and duration of serum IL-1 and IL- 6 are reliable indicators for early predicting the prognosis of SAP and evaluating the degree of inflammatory response. Results of this study showed that, after $24 \mathrm{~h}$ from surgery, compared with model group, the serum TNF- $\alpha$ level in high-dose baicalin group, IL-1 level in middleand high-dose baicalin groups, and IL-6 level in low-, middle- and high-dose baicalin groups were significantly decreased, respectively $(P<$ $0.05)$. This indicates that, baicalin can decrease the serum TNF- $\alpha$, IL- 1 and IL- 6 levels, thus alleviating the SAP in rats.

T lymphocytes play an important role in the human immune system, which execute the specific cellular immunity and regulatory functions. $\mathrm{CD}_{3}$ is a common differentiation antigen of all mature $T$ cells, and is expressed on the surface of mature $T$ cells. $C D_{3}$ is an important marker for the identification of $T$ cells. The $\mathrm{CD}_{3}$ molecule is also linked to the $T$ cell antigen receptor and participates in the signal transduction of $T$ cells ${ }^{18}$. $\gamma \delta T$ cells are a special subgroup of $T$ cells. It is found that, $\gamma \delta T$ cells can regulate the immune response, and play an important role in the production and maintenance of anti-infectious immunity, autoimmune diseases and immune tolerance of organ transplantation ${ }^{19}$. In the present study, compared with model group, the peripheral blood CD3 and $\gamma \delta T$ cell percentages in high-dose baicalin group were significantly increased, respectively $(P<0.05)$. This suggests that, baicalin can improve the cellular immune response of the body, thus exerting antiinflammatory effects.

Oxidative stress is involved in many pathophysiological processes of the body. SOD is an important antioxidant enzyme in the body. It can catalyze the transformation of oxygen free radicals to hydrogen peroxide, thus avoiding the damage to cells ${ }^{20}$. GSH$P x$ is a kind of antioxidant enzyme which can scavenge the free radicals and inhibit the free radical reaction ${ }^{21}$. MDA is one of the final products of cell membrane lipid peroxidation. It indirectly reflects the degree of cell membrane peroxidation ${ }^{22}$. Results of this study showed that, compared the model group, the SOD and GSH-Px levels in middle- and high-dose baicalin groups were significantly increased, respectively ( $P<0.05)$, and the MDA levels in middle- and high-dose baicalin groups were significantly decreased, respectively ( $P$ $<0.05)$. This indicates that, baicalin has the ability of scavenging radical and reducing lipid peroxidation, thus playing a role in pancreatic protection in SAP rats.

PKD is a novel serine/threonine protein containing 3 subtypes including PKD1, PKD2 and PKD3, in which PKD1 and PKD2 play an important role in the body natural immune response. PKD1 can be used as a downstream protein of NF-kappa B, and is involved in inflammatory reaction ${ }^{23}$. NF-kB is an important factor in cell signal transduction. It is a participation factor of immune response, inflammation, stress, epidemic prevention, tissue injury, apoptosis and so $\mathrm{on}^{24}$. In stimulation by infection and injury, the upstream signals induce the activation of NF-kB, and the activated NF-kB 
initiates the transcription of many genes. For example, NF-kB initiates the transcription of inflammatory factor genes, which accelerates the expression of inflammatory cytokines, and the inflammatory cytokines can also further stimulate NF-kB activation. This causes the explosive chain reaction, finally inducing the local tissue inflammation and resulting in tissue necrosis ${ }^{25}$. In this study, compared with model group, the PKD1 and NF-KB protein expression levels in middle- and high-dose baicalin group were significantly decreased, respectively $(P<$ 0.05). This indicates that, baicalin can downregulate the expression of PKD1 and NF-KB protein expressions, thus preventing the SAP in rats.

\section{Conclusion}

Baicalin can resist the inflammatory reaction and oxidative stress, and downregulate protein kinase D1 and nuclear factorkappa B protein expressions, thus exerting the protective effects on severe acute pancreatitis in rats.

\section{References}

1 Singh VK, Wu BU, Bollen TL, Repas K, Maurer R, Mortele KJ, Banks PA. Early systemic inflammatory response syndrome is associated with severe acute pancreatitis. Clin Gastroenterol Hepatol. 2009;7:124751. doi: 10.1016/j.cgh.2009.08.012.

2 Young SP, Thompson JP. Severe acute pancreatitis. JAMA. 2004;292:1305; author reply 1305. doi: 10.1001/ jama.292.11.1305-a

3 Zyromski NJ, Mathur A, Pitt HA, Lu D, Gripe JT, Walker JJ, Yancey K, Wade TE, Swartz-Basile DA. A murine model of obesity implicates the adipokine milieu in the pathogenesis of severe acute pancreatitis. Am J Physiol Gastrointest Liver Physiol. 2008;295:G5528. doi: 10.1152/ajpgi.90278.2008.

4 Feng NP, Di B, Liu WY. Comparison of the metabolism of baicalin in rats orally administered with Radix scutellariae extract and Shuang-Huang-Lian extract. Chem Pharm Bull (Tokyo). 2005;53:978-83. doi: 10.1248/cpb.53.978.

5 Cui L, Feng L, Zhang ZH, Jia XB. The anti-inflammation effect of baicalin on experimental colitis through inhibiting TLR4/NF-KB pathway activation. Int Immunopharmacol. 2014;23:294-303. doi: 10.1016/j.intimp.2014.09.005.

6 Shieh DE, Liu LT, Lin CC. Antioxidant and free radical scavenging effects of baicalein, baicalin and wogonin. Anticancer Res. 2000;20:2861-5. PMID: 11062694.

7 Orzechowska B, Chaber R, Wiśniewska A, Pajtasz-Piasecka E, Jatczak B, Siemieniec I, Gulanowski B, Chybicka A, Błach-Olszewska Z. Baicalin from the extract of Scutellaria baicalensis affects the innate immunity and apoptosis in leukocytes of children with acute lymphocytic leukemia. Int Immunopharmacol. 2014;23:558-67. doi: 10.1016/j.intimp.2014.10.005.

8 Zhang Y, Liao P, Zhu M, Li W, Hu D, Guan $\mathrm{S}$, Chen L. Baicalin attenuates cardiac dysfunction and myocardial remodeling in a chronic pressure-overload mice model. Cell Physiol Biochem. 2017;41:849-64. doi: 10.1159/000459708.

9 Yu FY, Huang SG, Zhang HY, Chi HG, Zou Y, Lu RX, Zheng XB. Effect of baicalin on signal transduction and activating transcription factor expression in ulcerative colitis patients. Chin J Integr Trad West Med. 2015;35:419-24. PMID: 26043563.

10 Kyo R, Nakahata N, Sakakibara I, Kubo $M$, Ohizumi Y. Baicalin and baicalein, constituents of an important medicinal plant, inhibit intracellular $\mathrm{Ca} 2+$ elevation by reducing phospholipase $\mathrm{C}$ activity in C6 rat glioma cells. J Pharm Pharmacol. 1998;50:1179-82. PMID: 9821667.

11 Minami M, Yoshikawa H. A simplified assay method of superoxide dismutase activity for clinical use. Clin Chim Acta. 1979;92:337-42. PMID: 436274.

$12 \mathrm{DE} P, \mathrm{WN}$ V. Studies on the quantitative and qualitative characterization of erythrocyte glutathione peroxidase. J Lab Clin Med. 1967;70:158-69. PMID: 6066618.

13 Placer ZA, Cushman LL, Johnson BC. Estimation of product of lipid peroxidation (malonyl dialdehyde) in biochemical systems. Anal Biochem. 1966;16:359-64. 
doi: 10.1016/0003-2697(66)90167-9.

14 Chen CC, Wang SS, Lee FY. Action of antiproteases on the inflammatory response in acute pancreatitis. JOP. 2007;8:488-94. PMID: 17625305.

15 To SQ, Knower KC, Clyne CD. Origins and actions of tumor necrosis factor $\alpha$ in postmenopausal breast cancer. J Interferon Cytokine Res. 2013;33:335-45. doi: 10.1089/ jir.2012.0155.

16 Malleo G, Mazzon E, Siriwardena AK, Cuzzocrea S. Role of tumor necrosis factor-alpha in acute pancreatitis: from biological basis to clinical evidence. Shock. 2007;28:130-40. doi: 10.1097/ shk.0b013e3180487ba1.

17 Chi DZ, Chen J, Huang DP. Influence of interleukin-1beta and interleukin- 6 gene polymorphisms on the development of acute pancreatitis. Genet Mol Res. 2015;14:97580. doi: 10.4238/2015.February.3.5.

18 Dykhuizen M, Ceman J, Mitchen J, Zayas M, Macdougall A, Helgeland J, Rakasz $E$, Pauza CD. Importance of the CD3 marker for evaluating changes in rhesus macaque CD4/CD8 T-cell ratios. Cytometry. 2000;40:69-75. doi: 10.1002/(SICI)10970320(20000501)40:13.0.CO;2-7.

19 Janis EM, Kaufmann SH, Schwartz RH, Pardoll DM. Activation of $\gamma \delta$ T cells in the primary immune response to Mycobacterium tuberculosis. Science. 1989;244:713-6. doi: 10.1126/science. 2524098.

20 Whitacre CM, Cathcart MK. Oxygen free radical generation and regulation of proliferative activity of human mononuclear cells responding to different mitogens. Cell Immunol. 1992;144:287-95. doi: 10.1016/0008-8749(92)90245-K.

21 Barja G, Cadenas S, Rojas C, Pérez-Campo $R$, López-Torres $M$. Short-term caloric and carbohydrate restriction increases GSH$\mathrm{Px}$ and cytochrome oxidase and decreases ascorbate in the mouse kidney. Free Radic Biol Med. 1993;15:539. doi: 10.1016/08915849(93)90440-6.

22 Gaweł S, Wardas M, Niedworok E, Wardas P. Malondialdehyde (MDA) as a lipid peroxidation marker. Wiadomosci Lekarskie. 2004;57:453-5. PMID: 15765761.

23 Chen Jun, Giridhar KV, Zhang L, Xu S, Wang QJ. A protein kinase $C /$ protein kinase $D$ pathway protects LNCaP prostate cancer cells from phorbol ester-induced apoptosis by promoting ERK1/2 and NF-KB activities. Carcinogenesis. 2011;32:1198-206. doi: 10.1093/carcin/bgr113.

24 Ray A, Siegel MD, Prefontaine KE, Ray P. Anti-inflammation: direct physical association and functional antagonism between transcription factor NF- kappa B and the glucocorticoid receptor. Proc Natl Acad Sci U S A. 1994;91:752-6. doi: 10.1073/ pnas.91.2.752.

25 Gadaleta RM, Oldenburg B, Willemsen EC, Spit M, Murzilli S, Salvatore L, Klomp LW, Siersema PD, van Erpecum KJ, van Mil SW. Activation of bile salt nuclear receptor FXR is repressed by pro-inflammatory cytokines activating NF-KB signaling in the intestine. Biochim Biophys Acta. 2011;1812:851-8. doi: 10.1016/j.bbadis.2011.04.005.

\section{Correspondence:}

Dr Yi Chen

Department of General Surgery, The Children's

Hospital

School of Medicine, Zhejiang University

57 Bamboo Alley, Hangzhou 310052 China

Phone: +86-571-88873023

6193006@zju.edu.cn

Received: Mar 18, 2018

Review: May 15, 2018

Accepted: June 14, 2018
Conflict of interest: none

Financial source: none
${ }^{1}$ Research performed at Central Laboratory, The Children's Hospital, School of Medicine, Zhejiang University, Hangzhou, China. 